\title{
First Prospective Cross-Sectional Study on the Impact of Immigration Background and Education in Early Detection of Breast Cancer
}

\author{
Elna Kuehnle $^{\mathrm{a}}$ Wulf Siggelkow $^{\mathrm{b}}$ Kristina Luebbe ${ }^{\mathrm{b}}$ Iris Schrader ${ }^{\mathrm{b}}$ \\ Karl-Heinz Noeding ${ }^{c}$ Stefanie Noeding ${ }^{d}$ Thomas Noesselt ${ }^{e}$ Peter Hillemanns ${ }^{a}$ \\ Thilo Dörk $^{\mathrm{a}}$ Tjoung-Won Park-Simon ${ }^{\mathrm{a}}$ \\ aDepartment of Gynecology and Obstetrics, Hannover Medical School, Hannover, Germany; \\ ${ }^{b}$ DIAKOVERE Henriettenstift, Breast Center, Hannover, Germany; ${ }^{c}$ HELIOS Klinikum Hildesheim, Breast Center,

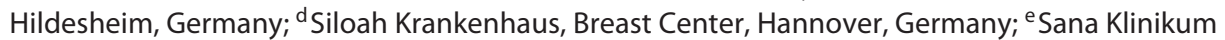 \\ Hamel-Pyrmont, Breast Center, Hameln, Germany
}

\section{Keywords}

Breast cancer · Immigrants · Early detection programs . Mammography screening $\cdot$ Education and immigration background

\begin{abstract}
Background: Although immigrant health is an important issue in national health policy, there is a serious shortage of data in many countries. Most studies lack information on educational status, which is a major limitation. This prospective cross-sectional study analyzed a real-world breast cancer population on the influence of immigration background and educational status on participation in breast cancer early detection programs in the federal state of Lower Saxony, Germany. Methods: Data collection was conducted from 2012 to 2016 in six certified breast cancer centers using a standardized questionnaire for patients' interview and tumorspecific data from the patients' medical records. Results: $2,145 / 3,047$ primary breast cancer cases were analyzed. $17.5 \%$ of our patients had a history of immigration, including $n=202$ first-generation immigrants and $n=168$ second-generation immigrants. Most of them were citizens of EU27 member states. No significant difference was seen in age, tumor stage, histology, grading, Ki-67, Her2/neu-status, and hormone receptor status compared to the native cohort. $100 \%$ participation rate in the breast cancer early detection
\end{abstract}

programs were seen in patients with no school graduation. With regards to the national mammography screening program, participation decreased significantly with educational status ( $p=0.0003$ ). Conclusions: No tumor biological differences were seen between immigrants and German natives. In first-generation immigrants, early detection programs were well accepted despite sociocultural and language differences. Participation rate decreased significantly with higher education levels irrespective of country of origin. Immigration background does not have a negative effect on the participation in breast cancer screening. This mainly relates to immigrants from EU27 member states.

(c) 2020 S. Karger AG, Basel

\section{Introduction}

Breast cancer is the most common female malignancy worldwide [1] with a growing demand for more specific diagnostic tools and more effective medicine. However, national health care systems are facing even greater challenges.

It is undisputed that early detection and treatment are vital for survival and prognosis of breast cancer. Organized mammography screening has a long tradition in Europe. In the 1980s mammography was proposed for early detection of breast cancer. Ever since then opportu- 
nistic screening has been widely used in Germany. In order to improve quality and ensure population-wide access an organized national mammography screening program based on the European guidelines was implemented for women aged 50-69 years in 2004. A participation rate of at least $70 \%$ regardless of the country of origin of the women is required [2]. In 2005/2006 the overall mammography screening participating rate was $59.7 \%$ in Lower Saxony, Germany [3]. A recent analysis demonstrated a $25.8 \%$ reduction of breast cancer mortality due to screening mammography for women between 50 and 59 years who followed the invitation [4].

Since the 1960s, Germany has been a country of immigration. First, immigrant workers were invited from countries like Italy, Greece, Turkey and others. Later, after the fall of the Iron Curtain and the reunification of Germany, mostly immigrants with German roots from Eastern European countries came to the country. In recent years, a growing number of immigrants fleeing war, violence, and poverty have come to Germany for humanitarian reasons [5].

Today immigration to Germany is rising. In 2015 approximately 2.02 million immigrants were registered. This is an increase of $50.2 \%$ compared to 2014 [6]. $45 \%$ of the immigrants were from the EU. The new increasing flow of immigrants from Syria and other war zones since 2015 will mean an even greater gain of immigrants in the next years. Immigrants are more likely to have a belowaverage income, a lower education, as well as unfavorable working and living conditions [7]. Integration of immigrants into the German health care system and maintaining the equal standards of quality within the medical field will become major issues not only in political but also medical debates concerning integration.

A retrospective analysis of 221 studies found being a recent immigrant, being foreign-born, and facing language barriers to be associated with non-use of mammography screening [8]. There is little to no data on the influence of immigration status, educational background, and participation in the breast cancer early detection programs. Spallek et al. [9] stated that low participation of immigrants in prevention programs can partly be attributed to specific access barriers. These barriers have become apparent in different ways depending on background, cultural and religious origins, length of residency in Germany, language skills, gender, and education as well as social status of the immigrant group concerned. In general, socioeconomic factors and educational levels influence the stage of tumor detection and consequently the rate of survival [10]. Other studies found that women of ethnic minorities, lower social status, and lower education present with a later stage of cancer and are less favored by the health care system $[11,12]$. Numerous studies focus on the relationship between socioeconomic sta- tus and higher tumor stage of breast cancer on diagnosis, worse prognosis, and a higher mortality $[11,13,14]$. Sprague et al. [15] also found that education levels are associated with the stage at diagnosis and that women with lower levels of education experience poorer survival in the US.

However, only little is known to what extent immigrants make use of breast cancer early detection services and whether this relates to school education. In this first prospective cross-sectional trial, we addressed these aspects by comparing the percentage of breast cancer detection modi throughout our whole study population of breast cancer patients. Patients from six certified breast centers in urban and rural districts of Lower Saxony, Germany were included.

\section{Methods}

Between 2012 and 2016, data was collected from 6 certified breast cancer centers in the region of Hannover, Hameln, Hildesheim, and Stadthagen, Germany. All patients diagnosed with breast cancer were offered to participate in the study. In case of approval, they were asked to sign a consent form and were interviewed by medically trained personnel according to a personal questionnaire. This questionnaire was exclusively developed for this study and included the following topics: demographic and personal medical history like pregnancies, births, hormone therapy, for example, and family history including country of origin, siblings, and family disposition to cancer. A second questionnaire was developed to address immigration status and education, as well as questions concerning the mode of tumor detection and knowledge about early detection and the mammography screening program.

Independently, data from the patient's hospital documents were collected. This included surgery report, pathology report, tumor conference decisions, and other breast cancer-related data. All data was documented and archived through eCRFs in a professional web-based data documentation system (secuTrial, http:// www.secutrial.com).

The study collective was divided into two groups of immigrants and one control group. The immigrant's group was divided into first- and second-generation immigrants. First-generation immigrants are immigrants that immigrated to Germany themselves. Second-generation immigrants are children of at least one parent with a history of immigration. The control group consists of native Germans. Natives are people that are born in Germany, have the German citizenship from date of birth, and whose parents are both born in Germany and have the German citizenship from date of birth.

The following parameter and prognostic factors were analyzed in all 3 groups: age, histology, stage of tumor, grading, proliferation marker Ki-67, Her2/hormone receptor status.

In-depth data was collected with regards to the mode of breast cancer detection (self-palpation, sonography, opportunistic/routine, or screening mammography) in first- and second-generation immigrants compared to natives. These data were correlated with educational qualifications.

Statistical analysis was conducted by the Institute of Statistics, Leibnitz University Hanover using the statistics program R (http:// www.cran.r-project.org). First, data was descriptively processed 


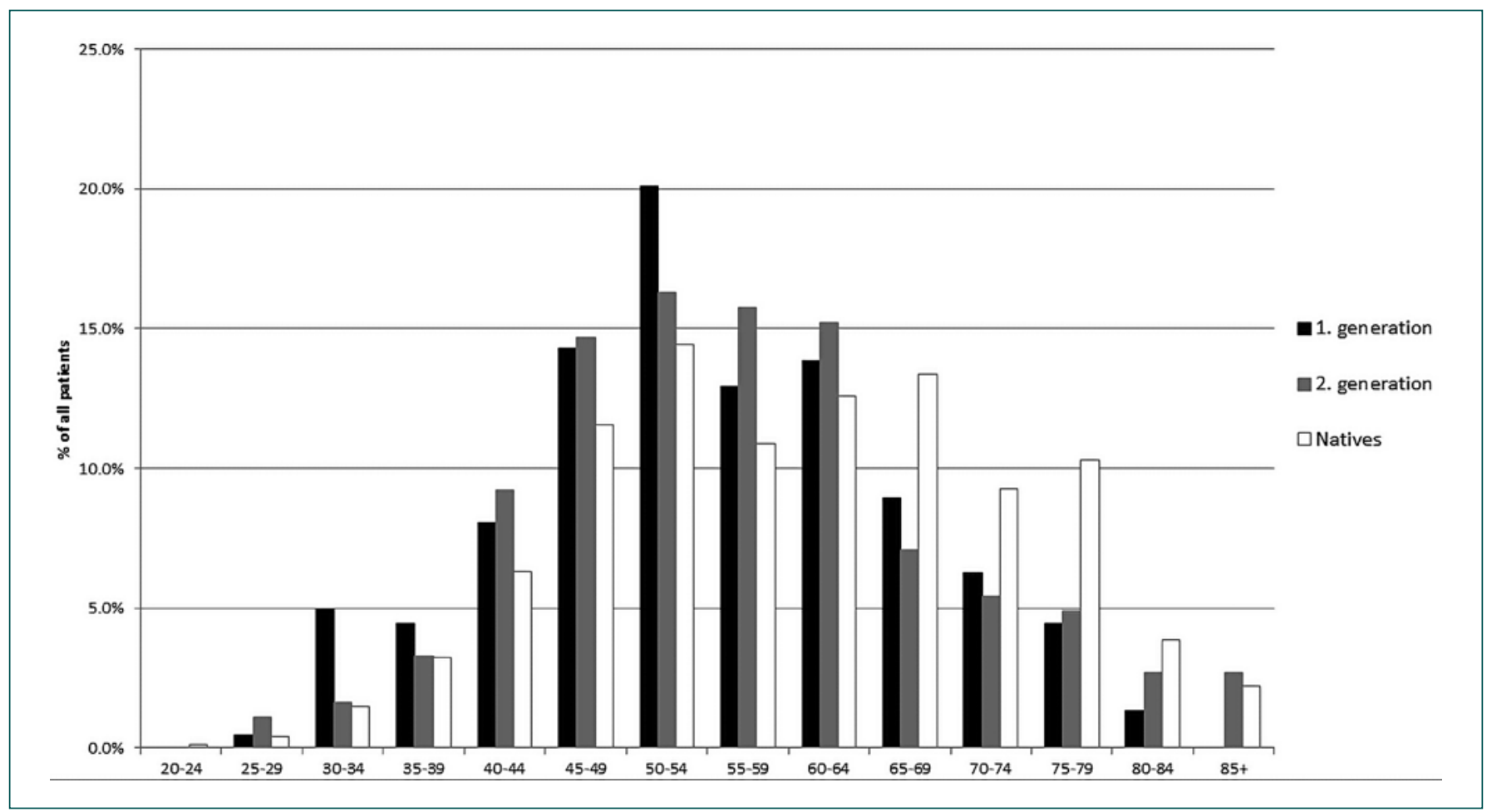

Fig. 1. Age distribution of the study population.

and described. Later, correlation analysis was conducted and the significance of correlations was tested. $\chi^{2}$ independency test was used to test for correlation using the corrected coefficient of contingency. Finally, a logistic regression model was applied to test for multiple variables.

\section{Results}

3,047 patients were included in the study. After excluding patients with incomplete questionnaire, no questionnaire, or recurrent breast cancer, data of 2,145 patients were eligible for analysis. The study collective consisted of $17.2 \%(n=370)$ immigrants and $82.8 \%(n=$ $1,775)$ German natives. The group of first-generation immigrants $(n=202 ; 9.4 \%)$ showed a wide spectrum of countries of origin with the largest group of EU27 immigrants. The group of second-generation immigrants $(n=$ $168 ; 7.8 \%)$ showed an even larger number of EU27 immigrants with more than $80 \%$.

The median age was 58 years. Compared to German natives, immigrants are less represented in the older patients (Fig. 1).

Tumor characteristics, i.e., tumor stage UICC [16], histology, tumor grade, hormone receptor/Her2 status, and Ki67, were analyzed in all three groups.

Stage IA was the most common stage throughout all groups. Stage IIA came second. DCIS (stage 0) was less common in natives and second-generation immigrants compared to first-generation immigrants (10\% vs. $16 \%)$. Statistically this was not significant $(p=0.47)$. Invasive ductal carcinomas were the most common subtype in natives as well as immigrants. Among invasive breast cancers G2 was the dominating grade in all groups followed by G3. No significant difference was seen between natives, first- and second-generation immigrants $(p=0.14)$. Comparing hormone receptor status and Her2neu status there was also no difference $(p=0.15)$. Ki67 status also showed no significant difference $(p=0.26)$. In summary, despite numeric differences there was no statistical difference between the three groups in tumor biology.

Distribution of educational background was nearly similar between natives and second-generation immigrants. In contrast, the distribution in the first-generation immigrants differs distinctively. The percentage of academics in the group of first-generation immigrants was significantly higher $(21.3 \%)$ compared to natives $(13.8 \%)$ and second-generation immigrants (14.9\%) $(p=0.0000)$.

The majority of the patients reported that the tumor was detected by self-palpation (44.7\%). $49.6 \%$ of the patients were high school graduates and $50 \%$ had no school graduation. Women with no school graduation were also represented strongest in the group of incidental detection $(30.8 \%)$ and least represented in the group of early detection. However, there was no significant correlation between educational background and mode of tumor detec- 


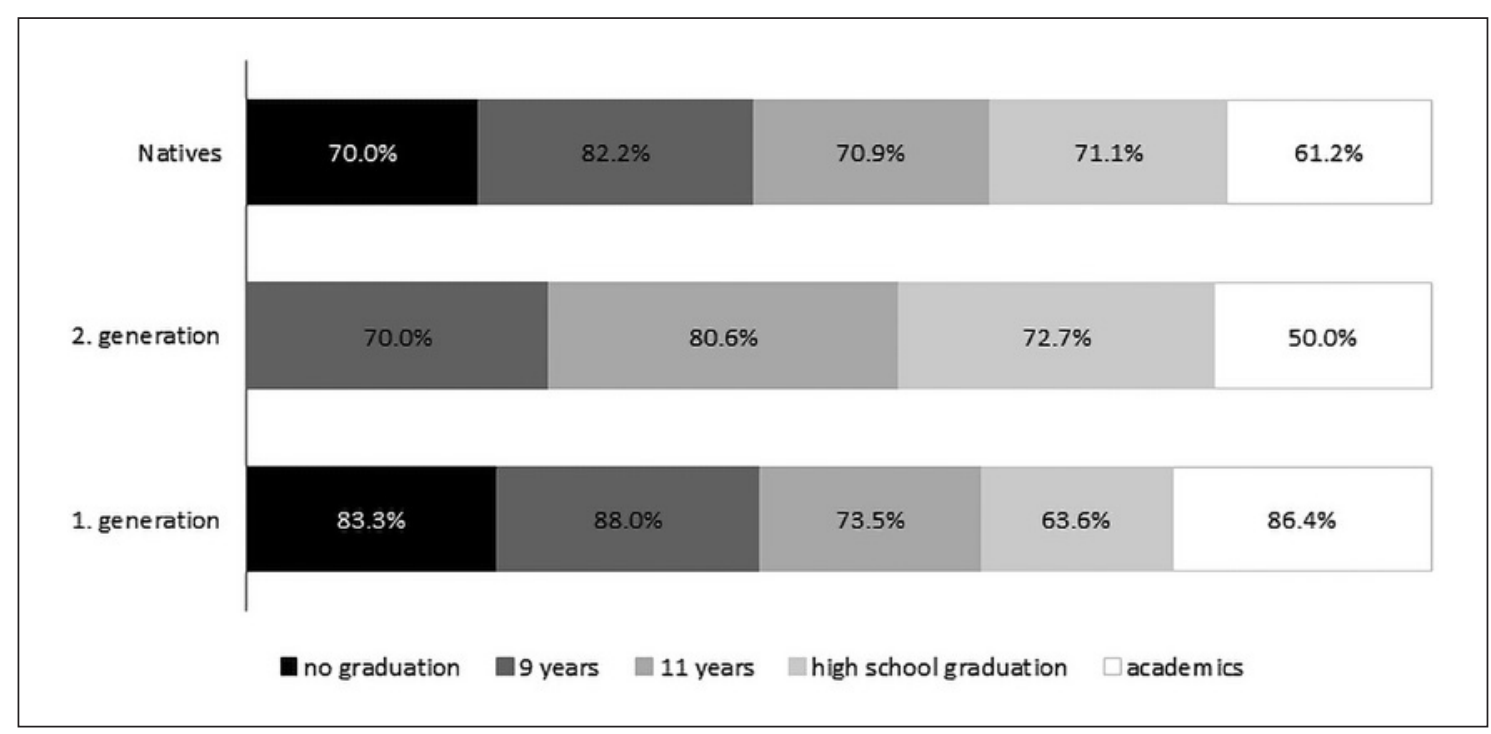

Fig. 2. Participation rate of breast cancer patients (\%) in the mammography screening program according to education background between the 3 groups (natives, first-generation immigrants, and second-generation immigrants).

tion $\left(\mathrm{K}^{*} 0.13, p=0.08\right)$. Self-palpation was the main mode of tumor detection among women between 20 and 50 years as well as older women from 70 years upwards. Among women aged 50 to 69 years, the tumor was most frequently detected by either opportunistic or organized mammography screening. All other forms of detection were irrelevant. There was a significant correlation between age and mode of tumor detection $\left(\mathrm{K}^{*} 0.43, p=\right.$ 0.0000).

Participation in the organized mammography screening program, at least once, was analyzed for all 3 groups (Fig. 2). Participation was high in all 3 groups with over $73 \%$. Highest participation rate $(80.4 \%)$ was seen for firstgeneration immigrants. Immigration status did not have an effect on participation rate $(p=0.13)$. In contrast, there was a significant inverse correlation between education status and participation rate $(p=0.0002)$. Participation rate decreased with increasing educational status.

All patients were asked if they had knowledge about early detection programs of breast cancer. $91.4 \%$ of all patients felt informed and answered the question with "Yes." $91.8 \%$ of the natives were informed compared to $90.9 \%$ of the second-generation immigrants and $88.4 \%$ of the first-generation immigrants. But this did not reach statistical significance. After correlating educational background with information status, we did see a significant influence of educational background on information status for all groups $(p=0.03)$. Patients with less education felt less informed about the screening programs irrespective of country of origin.

Despite differences among groups, the level of education did not significantly correlate with tumor stage. In the group of academics and high school graduates over $40 \%$ of the tumors were stage I. Advanced tumor stages (stage III and IV) were more frequently seen in the group with no school education. But no statistical significance was reached $(p=0.30)$. Immigration status did not have a significant influence on tumor stage and detection.

\section{Discussion}

This prospective cross-sectional study provides novel and in-depth information about women diagnosed with primary breast cancer in Germany. Our data is in line with the data from the partial census of the Federal Statistics Department in 2014. A total of 16.4 million people had an immigrant background, which corresponds to about $20 \%$ of the German population [17]. In our study $17.2 \%$ of our patients had an immigrant background. Thus the composition of the patients is likely to be representative of the overall population in Germany.

No difference was seen between the three study groups with regards to tumor biology. This finding is similar to results from Sweden, where no increased overall risk for breast cancer was seen for immigrants [18], although the same group found that the age at diagnosis of breast cancer in immigrants is earlier than in natives of Sweden, suggesting that true biological factors underlie the differences [19]. Studies from the United States and Canada found differences in stage at diagnosis and survival depending on race and ethnicity that could be statistically accounted for by intrinsic biological differences such as lymph node metastasis, distant metastasis, and triple- 
negative subtype [20-22]. But differences in the ethnic composition of the American and Canadian immigrant population as well as native population compared to the German native and immigrant population have to be taken into account. A large amount of immigrants to the United States and Canada have their country of origin in Asia or are of Hispanic or Afro-American background, whereas immigrant groups in Germany mostly consist of EU27 immigrants. Due to small numbers no detailed subgroup analysis was conducted in our study. Therefore differences in tumor biology of certain ethnic minorities might not be reflected. Analysis of the immigrant subgroup of "resettlers" (a group of immigrants in Germany that are ethnic Germans who emigrated to Russia and other Eastern European countries in the 17th-19th century and re-emigrated to Germany after the fall of the iron curtain) from the Former Soviet Union (FSU), which also represent a certain percentage of our study population, showed a lower breast cancer mortality compared to Germany's general population and similar to the FSU population, implicating an influence of pre-migration factors [23] other than ethnicity that might not be reflected in differences in tumor biology.

Interestingly, older age groups are less represented in the first-generation immigrants of our study population (Fig. 1). Reasons for this can be found in the age distribution of immigrants in Germany. In general, today, over $20 \%$ of the people below 45 years have an immigration background, whereas the group above 65 years only consists of $9.7 \%$ immigrants [6]. Therefore we do not see that many breast cancer cases in the older age groups of immigrants.

Today the mammography screening reaches far more than $50 \%$ of all female citizens in Lower-Saxony, Germany, between 50 and 69 years. The numbers of advancedstage breast cancer have decreased significantly in the last 10 years [3]. Most breast cancer cases are diagnosed in stage I. This effect is also reflected in the study population. There is no difference between native-born Germans and immigrants, more than $50 \%$ of the cancer cases were diagnosed in stage I or 0 . This finding suggests that preventive health care programs are accepted among first- and second-generation immigrants and no inequality is apparent. This is in consistency with von Au et al. [24], who also found no evidence of restricted access to or participation in preventive healthcare activities for migrant women. However, their study only included immigrants with Anatolian background. Therefore, their findings cannot be extrapolated to all immigrants in Germany today. In Norway, a significant difference in mammography screening participation was observed between immigrants and natives by Latif et al. [25]. A Swedish study [26] found a tendency of immigrants from countries with a low breast cancer risk to present with a higher stage compared to Swedes, which according to the authors may depend on their lower participation in the mammography-screening program.

Studies from outside Europe, from countries with a long-term history of immigration like Australia, showed that women from non-English-speaking backgrounds have a $5 \%$ lower participation rate in mammography screening programs [27] and a worse outcome [28].

Vahabi et al. [29] found that breast cancer screening uptake varies among immigrant women depending on the world region of origin. Immigrants from countries with a lower overall breast cancer risk may perceive their risk to be lower than women born in countries with higher incidences and therefore are less likely to participate in mammography screening programs [30]. Our study does not support this hypothesis. However, discrepant findings can be explained by different migration cycles, since global migration continues to evolve and becomes more complex, as well as different health care systems and immigration politics of the countries of immigration.

With regard to educational background we found a significantly higher percentage of women with an academic education in the group of first-generation immigrants compared to second-generation immigrants and natives. This finding could be due to immigration selection effects, favoring immigrants with higher education, or might be due to differences in interpretation of educational systems. However, the Bologna Accord of 1999 was an important step to unify different types of education systems. To date 48 countries have adopted the Bologna Process. In our study, the majority of the first-generation immigrants are from one of these countries, which adapted this process between 1999 and 2003 [31]. Also, moving to Germany for possibly better treatment for breast cancer is a thinkable explanation.

It is of note, that in the whole study population of breast cancer patients, first-generation immigrants with higher educational degrees participated in organized mammography screening significantly more often than natives and second-generation immigrants with similar education. A possible explanation might be that first-generation immigrants are still conditioned through a different invitation system for health care programs from their country of origin and thereby follow invitations more willingly.

Participation rate in organized mammography screening in this collective of newly diagnosed breast cancer patients decreased in natives and second-generation immigrants with higher educational attainment. Interestingly, more than $90 \%$ of both groups stated to be informed about organized and opportunistic screening, but only $73 \%$ participated. In contrast, $80 \%$ of all women with no school education participated in the organized mammography screening. This is consistent with other studies. 
Gummersbach et al. [32] found that less educated women are more willing to participate than more educated ones. This was also seen by Naß-Griegoleit et al. [33]. One possible explanation might be that women with a higher educational status are more critical and seek more detailed information. Also, the perceived risk of breast cancer might differ among these groups. Some women who can afford private insurances prefer opportunistic mammography at a clinic of their choice.

With regard to information on early detection programs we found no significant difference between natives and immigrants. This leads to the conclusion that despite linguistic difficulties screening programs are well accepted. Earlier studies documented significant inequalities, especially in mammography screening participation rates among immigrants. One of the explanations favored was lack of knowledge and language barriers [9, 34, 35]. In contrast to this, in our study lack of knowledge correlated with the level of education. These results are in concordance with Berens et al. [36], who conducted a study on informed choice in the German mammography screening program by education and migrant status. They found a decrease in intention to participate in the screening with increasing education and that the proportion of good knowledge was poorer with lower education status and migrant status. In contrast to Berens et al. [36] we found a much higher perceived information level in our study population, possibly due to methodological differences. We asked the patients whether they felt informed about mammography screening but did not actually test their detailed knowledge.

In conclusion, no difference was seen between firstand second-generation immigrants and native Germans with regards to tumor biology. Opportunistic and organized mammography screening was equally accepted in all groups despite sociocultural and linguistic differences. Participation rate decreased significantly with higher education level in all groups. Immigration status does not have a negative impact on participation in early detection programs of breast cancer in Germany. This finding mainly relates to immigrants from EU27 member states rather than immigrants from non-EU countries. Integrating the health needs of migrants into national plans is a major challenge. Further studies are needed to develop sustainable health care concepts for migrants and host communities.

\section{Acknowledgments}

We would like to thank Prof. Sibbertsen and Dr. Bertram, Institute of Statistics, Leibniz-University Hanover, for statistical analysis.

\section{Statement of Ethics}

Subjects have given their written informed consent. The study was approved by the ethical committee of the Hanover Medical School, Hanover, Germany.

\section{Conflict of Interest Statement}

The authors declare that they have no conflict of interest.

\section{Funding Sources}

No funding.

\section{Author Contributions}

E. Kuehnle: study design, data acquisition and interpretation, drafting. W. Siggelkow, K. Luebbe, I. Schrader, K.-H. Noeding, S. Noeding, T. Noesselt: acquisition of data, interpretation and revision. P. Hillemanns: data interpretation and revision. T. Dörk: study design, acquisition of data, data interpretation and revision. T.-W. Park-Simon: study design, data acquisition and interpretation, drafting.

\section{References}

1 RKI Beiträge zur Gesundheitsberichterstattung des Bundes: Krebs in Deutschland 2011/2012. RKI DOI: 10.17886/rkipubl2015-004.

2 Perry N, Broeders M, de Wolf C, Törnberg S, Holland R, von Karsa L. European guidelines for quality assurance in breast cancer screening an diagnosis. Fourth edition - summary document. Ann Oncol. 2008 Apr;19(4):61422.

3 Schwerpunkt Mammographie; Zehn Jahre Erfolg. Niedersächsisches Ärzteblatt 89 [cited 2018 Nov 25]. Available from: http://www. haeverlag.de/nae/n_beitrag.php?id=5200.
4 Uleer C. Deutsches Mammography-Screening Programm senkt Brustkrebs Mortalität. Frauenarzt 2020;61(4):264-6

5 Berlin Institut Neue Potentiale. Zur Lage der Integration in Deutschland. Berlin [cited 2018 Nov 25]. Available from: http://www. berlin-institut.org/fileadmin/user_upload/ Neue_Potenziale/Neue_Potenziale_online. pdf.

6 Bundesamt für Migration und Flüchtlinge Migrationsbericht. 2015 [cited 2018 Nov 25]. Available from: https://www.bamf.de/ SharedDocs/Anlagen/DE/Publikationen/Migrationsberichte/migrationsbericht-2015. pdf?_blob=publicationFile.
7 Razum O, Zeeb H, Meesmann U, Schenk L, Bredehorst M, Brzoska P, Dercks T, Glodny S, Menkhaus B, Salman R, Saß AC, Ulrich R. Migration und Gesundheit Schwerpunktbericht der Gesundheitsberichterstattung des Bundes. RKI DOI https://doi.org/10.25646/3119/rkipubl-2008-07-21.

8 Spallek J, Zeeb H, Razum O. Prevention among immigrants: the example of Germany. BMC Public Health. 2010 Feb;10(1):92.

9 Schueler KM, Chu PW, Smith-Bindman R. Factors associated with mammography utilization: a systematic quantitative review of the literature. J Womens Health (Larchmt). 2008 Nov;17(9):1477-98. 
10 Campbell RT, Li X, Dolecek TA, Barrett RE, Weaver KE, Warnecke RB. Economic, racial and ethnic disparities in breast cancer in the US: towards a more comprehensive model. Health Place. 2009 Sep;15(3):855-64.

11 Martins T, Hamilton W, Ukoumunne OC. Ethnic inequalities in time to diagnosis of cancer: a systematic review. BMC Fam Pract. 2013 Dec;14(1):197.

12 Chor JS, Lam HC, Chan A, Lee HM, Fok E, Griffiths S, et al. Socioeconomic disparity in breast cancer detection in Hong Kong - a high income city: retrospective epidemiological study using the Breast Cancer Registry. PLoS One. 2014 Oct;9(10):e107630

13 Molina Y, Silva A, Rauscher GH. Racial/ethnic disparities in time to breast cancer diagnosis: the mediating effects of health care facility factors. Med Care. 2015 Oct;53(10):872-8.

14 Yedjou CG, Tchounwou PB, Payton M, Miele L, Fonseca DD, Lowe L, et al. Assessing the racial and ethnic disparities in breast cancer mortality in the United States. Int J Environ Res Public Health. 2017 May;14(5):E486.

15 Sprague BL, Trentham-Dietz A, Gangnon RE, Ramchandani R, Hampton JM, Robert SA, et al. Socioeconomic status and survival after an invasive breast cancer diagnosis. Cancer. 2011 Apr;117(7):1542-51.

16 Wittekind, C, Meyer, HJ, Hrsg. TNM. Klassifikation maligner Tumoren. Weinheim: Wiley-VCH; 2010. 7. Auflage; p. 5.

17 Statistisches Bundesamt. Bevölkerung mit Migrationshintergrund - Ergebnisse des Mikrozensus 2014 - Fachserie 1 Reihe 2.2 2014. Available from https://www.statistischebibliothek.de/mir/receive/DEHeft_mods 00030531 [cited 2018 Nov 25].

18 Mousavi SM, Hemminki K. Cancer incidence, trends, and survival among immigrants to Sweden: a population-based study. Eur J Cancer Prev. 2015 Mar;24 Suppl 1:S163.

19 Hemminki K, Mousavi SM, Sundquist J, Brandt A. Does the breast cancer age at diagnosis differ by ethnicity? A study on immigrants to Sweden. Oncologist. 2011;16(2): $146-54$
20 Warner ET, Tamimi RM, Hughes ME, Ottesen RA, Wong YN, Edge SB, et al. Racial and ethnic differences in breast cancer survival: mediating effect of tumor characteristics and sociodemographic and treatment factors. J Clin Oncol. 2015 Jul;33(20):2254-61.

21 Iqbal J, Ginsburg O, Rochon PA, Sun P, Narod SA. Differences in breast cancer stage at diagnosis and cancer-specific survival by race and ethnicity in the United States. JAMA. 2015 Jan;313(2):165-73.

22 Iqbal J, Ginsburg O, Fischer HD, Austin PC, Creatore MI, Narod SA, et al. A populationbased Cross-Sectional Study comparing breast cancer stage at diagnosis between immigrant and Canadian-born Women in Ontario. Breast J. 2017 Sep;23(5):525-36.

23 Kyobutungi C, Ronellenfitsch U, Razum O, Becher H. Mortality from cancer among ethnic German immigrants from the Former Soviet Union, in Germany. Eur J Cancer. 2006 Oct;42(15):2577-84.

24 von Au A, Weiler U, Stefanovic S, Wallwiener M, Heil J, Golatta M, et al. Breast cancer presentation and therapy in migrant versus native German patients: contrasting an convergent data of a retrospective monocentric study. Arch Gynecol Obstet. 2016 Jul;294(1): 145-52.

25 Latif F, Helgeland J, Bukholm G, Bukholm IR. Ethnicity differences in breast cancer stage at the time of diagnosis in Norway. Scand J Surg. 2015 Dec;104(4):248-53.

26 Mousavi SM, Försti A, Sundquist J, Hemminki K. Ethnic differences in breast cancer risk and survival: A study on immigrants in Sweden. Acta Oncol 2013;52(8):1637-42.

27 Australian Institute of Health and Welfare 2015: BreastScreen Australia monitoring report 2012-2013. Cancer series No. 95. Cat. No. CAN 93. Canberra: AIHW [cited 2018 Nov 25].
28 Sze M, Butow P, Bell M, Vaccaro L, Dong S, Eisenbruch M, et al.; Psycho-oncology Cooperative Research Group Culturally and Linguistically Diverse (CALD) TEAM. Migrant health in cancer: outcome disparities and the determinant role of migrant-specific variables. Oncologist. 2015 May;20(5):523-31.

29 Vahabi M, Lofters A, Kumar M, Glazier RH. Breast cancer screening disparities among immigrant women by world region of origin: a population-based study in Ontario, Canada. Cancer Med. 2016 Jul;5(7):1670-86.

30 Ott JJ, Ullrich A, Mascarenhas M, Stevens GA. Global cancer incidence and mortality caused by behavior and infection. J Public Health (Oxf). 2011 Jun;33(2):223-33.

31 EHEA. www.ehea.info [cited 2018 Nov 25].

32 Gummersbach E, in der Schmitten J, Mortsiefer A, Abholz HH, Wegscheider K, Pentzek $\mathrm{M}$. Willingness to participate in mammography screening: a randomized controlled questionnaire study of responses to two patient information leaflets with different factual content. Dtsch Arztebl Int. 2015 Jan;112(5): 61-8.

33 Naß-Griegoleit I, Schultz-Zehden B, Klusendick M, Diener J, Schulte H. Studie belegt hohe Akzeptanz des Mammographie- Screenings bei Frauen. Ergebnisse der ersten repräsentativen Studie in Deutschland. Frauenarzt. 2009;50:494-501.

34 Kristiansen M, Thorsted BL, Krasnik A, von Euler-Chelpin M. Participation in mammography screening among migrants and nonmigrants in Denmark. Acta Oncol. 2012 Jan; 51(1):28-36.

35 Kristiansen M, Lue-Kessing L, Mygind A, Razum O, Norredam M. Migration from low- to high-risk countries: a qualitative study of perceived risk of breast cancer and the influence on participation in mammography screening among migrant women in Denmark. Eur J Cancer Care (Engl). 2014 Mar;23(2):206-13.

36 Berens EM, Reder M, Razum O, Kolip P, Spallek J. Informed choice in the German mammography screening program by education and migrant status: survey among firsttime invitees. PLoS One. 2015 Nov; 10(11):e0142316 